\title{
Biomarkers and weight changes in broiler chicks (Gallus domesticus) exposed to livestock feed containing residues of phostoxin and actellic pesticides
}

\author{
A. A. OTITOLOJU ${ }^{1 *}$, K.O. IGE ${ }^{1}$ and A. Z. ADEROLU ${ }^{2}$ \\ ${ }^{1}$ Dept. of Zoology, Faculty of Science, University of Lagos, Akoka, Lagos, Nigeria. \\ ${ }^{2}$ Dept. of Marine Sciences, Faculty of Science, University of Lagos, Akoka, Lagos, Nigeria. \\ *Corresponding author; E-mail: bayotitoloju@yahoo.com
}

\begin{abstract}
The acute and sublethal toxicity studies of two organophosphate pesticides were carried out against the broiler chicks, Gallus domesticus. On the basis of the computed toxicity factor, phostoxin with a 14 day LC50 values of $0.022 \mathrm{mg} / \mathrm{kg}$ was found to be 2 times more toxic than actellic (14 day LC50 of $0.048 \mathrm{mg} / \mathrm{kg}$ ). The results of the biochemical analysis of the blood samples of the broilers chicks exposed to sublethal doses of phostoxin and actellic over a 49 day period of exposure revealed that there was a significant $(\mathrm{P}<0.05)$ increase in the level of glucose from an average of $284.5 \mathrm{mg} / \mathrm{dL}$ to $337.9 \mathrm{mg} / \mathrm{dL}$ in exposed chicks. Similarly, lactate dehydrogenase $(\mathrm{LDH})$ level also increased significantly $(\mathrm{P}<0.05)$ from an average of 867 IU/L in control to 932.5 IU/L in the blood of exposed chicks. The levels of total protein in the blood of exposed chicks however decreased significantly $(\mathrm{P}<0.05)$ from an average of $7.07 \mathrm{mg} / \mathrm{dL}$ to $2.7 \mathrm{mg} / \mathrm{dL}$ in exposed chicks. The histopathology studies showed a high prevalence of hepatic vacuolation and lymphocytosis in the hepatocytes of livers for chicks exposed to sublethal doses of actellic and phostoxin. No visible lesion was however observed in the intestines of the exposed broiler chicks. The chicks exposed to sublethal doses of phostoxin and actellic were observed to gain weight over the period of observation and there was no significant $(\mathrm{P}>0.05)$ differences in weights of exposed and control chicks. The implications of these results in the management of poultry farm production and the potential use of glucose, total protein and LDH levels in blood of birds as biomarkers of exposure for organophosphate pesticide residue were discussed.
\end{abstract}

() 2010 International Formulae Group. All rights reserved.

Keywords: Organophosphate pesticides; Histopathology; Biomarkers; Poultry; Biochemical parameters.

\section{INTRODUCTION}

Broilers are specially developed breeds of domestic chicken with the ability for quick growth and high feed conversion efficiency. They weigh 1.5 to $1.8 \mathrm{~kg}$ and are considered to be mature after 42 to 49 days post hatch. Broiler meat is also an important source of high quality proteins and it is one of the most important sectors of Nigeria's economy that has experienced significant growth. Within the last two decades, poultry meat production has increased from 57,000 tonnes to 121,000 tones, indicating 112 percent increase over a period of 14 years, which clearly shows the prime importance of poultry production both as a source of protein and enterprise for employment or income generation (Alimi et al., 2006). 
In poultry production, pest activities represent a major constraint to productivity all over the world especially in Africa, where insects and rodents cause damage to grains and other food crops that are meant for poultry feed production both in the field and storage. Hodges (1972) reported that the total fraction of the total crop production lost to insects in Asia was $41 \%$ for rice, $18 \%$ for cotton, $14 \%$ for maize, $13 \%$ for vegetables and $6.5 \%$ for wheat, oats, barley and rye. In the United States, about $5-15 \%$ of total agricultural production is believed to be lost to insect pests. Also, pests such as rodents and mites may cause direct damage to the birds resulting in mortality and reduced poultry meat quality. In order to control these pests menace, pesticide application has been frequently deployed as a means for combating pest activities.

Despite the advantages arising from the use of pesticides, deleterious side effects usually occur from indiscriminate and overuse of the products. This results in drift of sprays during application resulting in severe damage and pesticide residue problems. The widespread use and misuse of pesticides in feed and grain crop, cultivation and preservation makes it almost inevitable that certain of these pollutants find their way into the feeding channels. When non-target organisms are exposed to pesticide residues, they may suffer acute or chronic toxic effects. Chronic toxicity involves exposure to sublethal concentrations over a long period of time resulting in subtle changes in the organism which may eventually result in mortality or adverse effects (Don-Pedro, 1980). Observations of these sublethal effects in exposed organisms are now being recognized as useful biological responses or biomarkers. Biomarkers are any biological response to an environmental chemical at the individual level or below, demonstrating a departure from the normal status. Some of the widely used biomarkers are histopathological changes, morphological changes, behavioural changes and blood biochemistry. The biochemical characteristics of blood are among the important indices of the status of the internal environment of organisms (Edsall, 1999), and these changes in the biochemical profile, mirror changes in the metabolic and biochemical processes of the organism. These biomarker studies enable environmental scientists to detect at an earlier stage the negative impacts of pollutants/diseases before advent of mass mortalities usually recorded during poultry operations.

On the basis of the above, the objectives of this study are to determine the acute and chronic effects of two organophosphate pesticides (phostoxin and actellic) on blood biochemistry, histopathology and weight changes in broiler chicks, Gallus domesticus that can serve as biomarkers of exposure to the pesticides in poultry farms.

\section{MATERIALS AND METHODS}

Test animals: selection and acclimatization

Newly hatched unsexed broiler chicks within weight range (60-110 g) were obtained from a poultry farm and housed in a deep litter brooder with ad libitum supply of feed and water. The cages were covered with a wire mesh for proper ventilation and to prevent escape of the chick. The cages were also cleaned daily. The chicks were randomly distributed into groups of five chicks each and allowed to acclimatize to the brooder environmental conditions $\left(28 \pm 2{ }^{\circ} \mathrm{C}, 79 \pm 2\right.$ $\mathrm{RH})$ for 7 days. At the end of the first week, the mean weight of each group was taken.

\section{Test chemicals}

Two organophosphate compounds were used for the experiment.

- Actellic; Chemical name is 0-[2(diethylamino)-6-methyl-4-pyrimidinyl] 0,0 dimethylphosphorothioate. It is as a pesticide used for long term storage of grain products. 
- Phostoxin; The synonyms are hydrogen phosphide, phosphorus hydride and phosphorus trihydride. It is also used as a pesticide for long term storage of grain products.

\section{General bioassay techniques}

Acute toxicity (mortality) of phostoxin and actellic against Gallus domesticus

For each test concentration, $100 \mathrm{~g}$ of feed was completely mixed with predetermined concentrations of the pesticides (phostoxin and actellic) and fed to the chicks at 4-6 h interval. There were 2 replicates of 5 chicks per treatment giving a total of 10 birds per test concentration or control. The control chicks were also fed $100 \mathrm{~g}$ of pesticide-free feed. Test concentrations are as follow:

- Phostoxin against Gallus domesticus at 0.05 $\mathrm{mg} / \mathrm{kg}, 0.25 \mathrm{mg} / \mathrm{kg}, 0.5 \mathrm{mg} / \mathrm{kg}$ and untreated control.

- Actellic against Gallus domesticus at 0.05 $\mathrm{mg} / \mathrm{kg}, 0.25 \mathrm{mg} / \mathrm{kg}, 0.5 \mathrm{mg} / \mathrm{kg}$ and untreated control.

Mortality was observed once every $24 \mathrm{~h}$ for 14 days.

Assessment of quantal response (mortality)

Chicks are taken to be dead if there is no respiratory movement, body movement and response to prodding with a blunt rod. Straddled leg was also used as a characteristic sign of mortality in the chicks.

Sublethal toxicity of phostoxin and actellic against Gallus domesticus.

A similar experiment as described above (under acute toxicity tests) was carried out, but for this bioassay, the chicks were exposed to sub-lethal concentrations $\left(1 / 10^{\text {th }}\right.$ and $1 / 100^{\text {th }}$ of 14 day $\mathrm{LC}_{50}$ ) of actellic and phostoxin. There were 10 replicates of 5 chicks per treatment giving a total of 50 chicks per test concentration or control.

During these sublethal tests, the setup was renewed every 4 days in order to maintain test concentrations over the 49 days observation period, ensure the freshness of the feed and cleanness of the environment. The chicks were fed everyday for 49 days of the period of experiment. Four chicks per test concentration were chosen randomly and sacrificed at different intervals (days 0, 14, 28 and 48). The following sublethal effect studies were carried out:

\section{Blood biochemistry}

At predetermined day intervals (days 0 , 14, 28 and 48), four live chicks per concentration and control were randomly selected and $2 \mathrm{ml}$ of blood was collected from the brachial wing vein using a $2 \mathrm{ml}$ butterfly syringe with 23 gauge needles. The blood was then transferred into lithium heparin bottles for glucose analysis and Ethylene Diamine Tetra Acetic acid (EDTA) bottles for total protein and lactate dehydrogenase (LDH) analysis. $2 \mathrm{mg}$ of the anticoagulants per $1 \mathrm{ml}$ of blood was used.

For plasma collection, samples of blood were centrifuged at $1500 \mathrm{rpm}$ for $20 \mathrm{~min}$ to separate the plasma. The total protein and albumin were estimated by modified Biuret method, glucose by glucose oxidase reaction (GOD), the activity of blood LDH was determined kinetically by the rate of formation of a blue chromophore complex.

\section{Histological studies}

For this studies, at predetermined day intervals (days 0, 28 and 49), four live chicks per test concentration or control were randomly selected and dissected. The intestine and liver were carefully removed and fixed in Buoin's fluid. The fixed samples were transferred to phosphate buffer $(\mathrm{pH}$ 6.8) after $7 \mathrm{~h}$ of fixation in Boiun's fluid. The tissues were then dehydrated in graded alcohol, cleared in xylene before embedding in paraffin wax (melting point $56.0^{\circ} \mathrm{C}$ ). Serial sections of 2-5 $\mu \mathrm{m}$ thickness was cut in rotary microtome then passed through xylene followed by absolute alcohol and water. The sections were stained with haematoxylin and eosin, dehydrated in graded alcohol, cleared in more xylene and mounted in Canada balsam. 
The slides were left to dry on the hot plate for $2 \mathrm{~h}$ before observation under the microscope.

\section{Weight changes studies}

On a weekly basis, all the chicks exposed per treatment including control were collected, placed in perforated weighing box of known weight and weighed with the aid of a top loading compact weighing balance. Weight of the box was then subtracted from the final weight to determine the actual weight of each chick.

\section{Statistics}

\section{Probit analysis}

The dose-response data was analyzed by probit analysis after Finney (1971). Probit analysis was based on a program by Ge-Le Pattouriel, Imperial College, London, as adopted by Don-Pedro (1989). The indices of toxicity measurement derived from this analysis are;

$\mathrm{LC}_{95^{-}}$Lethal concentration that causes 95\% responses (mortality) in exposed organisms.

$\mathrm{LC}_{50^{-}}$- Lethal concentration that causes $50 \%$ responses (mortality) in exposed organisms.

\section{Analysis of Variance (ANOVA)}

The Analysis of Variance (ANOVA) was carried out to compare several treatments mean at $5 \%(\mathrm{P}<0.05)$ level of significance for appropriately designed experiments using SPSS Package 13.

\section{RESULTS}

Acute toxicity studies of phostoxin and actellic against broiler chicks, Gallus domesticus

The derived 14-day LC50 value of phostoxin against the chicks was $0.022 \mathrm{mg} / \mathrm{kg}$ while that of actellic was $0.048 \mathrm{mg} / \mathrm{kg}$. Comparison of the derived 14-day $\mathrm{LC}_{50}$ revealed that phostoxin was significantly (no overlaps in $95 \%$ confidence limit) more toxic than actellic when tested against Gallus domesticus (Table 1). On the basis of the computed toxicity factor, phostoxin was found to be 2.18 times more toxic than actellic.

Sublethal studies of phostoxin and actellic against broiler chicks, Gallus domesticus Effect of phostoxin on blood parameters

The results of the biochemical analysis of the blood samples of the broilers chicks exposed to sublethal doses of phostoxin ( 0.002 and $0.02 \mathrm{mg} / \mathrm{kg}$ and control) over a 49 day period of exposure revealed that there was an increase in the levels of glucose and lactate dehydrogenase (LDH) in the blood of exposed chicks compared to control (Table 2). The glucose level was found to increase significantly $(\mathrm{P}<0.05)$ from an average of 287 $\mathrm{mg} / \mathrm{dL}$ in control chicks to $337.9 \mathrm{mg} / \mathrm{dL}$ in exposed chicks. Similarly, the LDH levels also increased significantly $(\mathrm{P}<0.05)$ from an average of $879 \mathrm{IU} / \mathrm{L}$ in control to $932.5 \mathrm{IU} / \mathrm{L}$ in exposed chicks. The levels of total protein in the exposed chicks were however found to decrease significantly $(\mathrm{P}<0.05)$ in the blood from an average of $4.0 \mathrm{mg} / \mathrm{dL}$ in control chicks to $2.7 \mathrm{mg} / \mathrm{dL}$ (Table 2).

\section{Effect of actellic on blood parameters}

The results of the biochemical analysis of the blood samples of broiler chicks exposed to sublethal doses of actellic (0.005 and 0.05 $\mathrm{mg} / \mathrm{kg}$ and control) over the 49 days period of exposure revealed that there was an increase in the levels of glucose and lactate dehydrogenase (LDH) in the blood of exposed chicks compared to control (Table 3). The glucose level was found to increase significantly $(\mathrm{P}<0.05)$ from an average of $284.5 \mathrm{mg} / \mathrm{dL}$ to $313.5 \mathrm{mg} / \mathrm{dL}$ in exposed chicks. Similarly, the LDH levels also increased significantly $(\mathrm{P}<0.05)$ from an average of $867 \mathrm{IU} / \mathrm{L}$ to $901 \mathrm{IU} / \mathrm{L}$ in exposed chicks. The levels of total protein in the exposed chicks was however found to decrease significantly $(\mathrm{P}<0.05)$ in the blood from an average of $7.07 \mathrm{mg} / \mathrm{dL}$ to $2.75 \mathrm{mg} / \mathrm{dL}$ in exposed chicks (Table 3 ). 


\section{Histopathological effects}

The results of the histopathological effects of phostoxin and actellic on the liver of the broiler chicks are shown in Fig. 1-3. The results show that there were various degrees of histological alterations observed in the liver cells (Fig. 2-3). There was a prevalence of foci of altered hepatocytes in the liver of the chicks exposed to sublethal concentrations of phostoxin (Fig. 2) and actellic (Fig. 3). Hepatocytes of test animals exposed to sublethal concentration of phostoxin were found to be vacuolated (Fig. 2) while the hepatocytes exposed to actellic were found to be vacuolated and also invaded by lymphocytes (Fig. 3).

\section{Weight changes studies}

Results of the exposure of broiler chicks to sublethal doses $\left(1 / 10^{\text {th }}\right.$ and $1 / 100^{\text {th }}$ of 14-Day $\mathrm{LC}_{50}$ values) of phostoxin and actellic over the 49-day experimental period are given in Fig. 4. The results showed that all the chicks exposed to the sublethal doses of phostoxin and actellic and control chicks increased in weight over the period of observation. Analysis of weight gained by ANOVA between the control and exposed chicks also revealed that there were no significant $(\mathrm{P}>0.05)$ differences in the weights of the chicks either on the basis of days of exposure or concentration of pesticides residue in their feed.

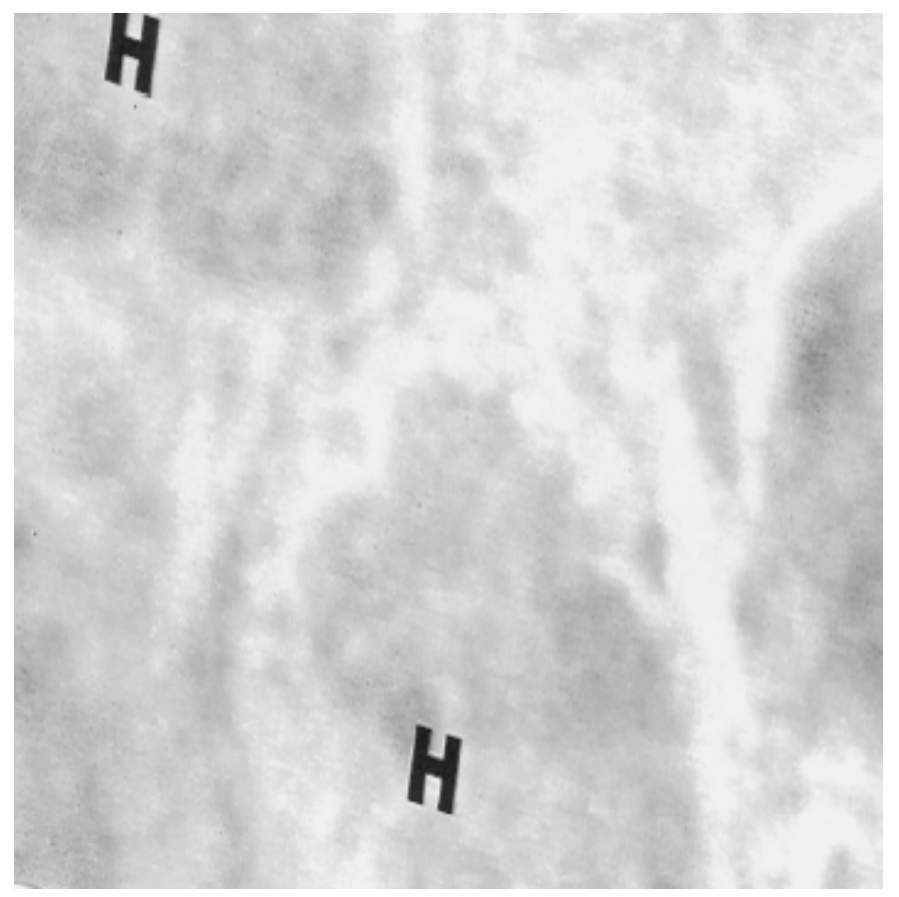

Figure 1: Liver of Gallus domesticus. Normal hepatocyte $(\mathrm{H})$ for control chicks. 


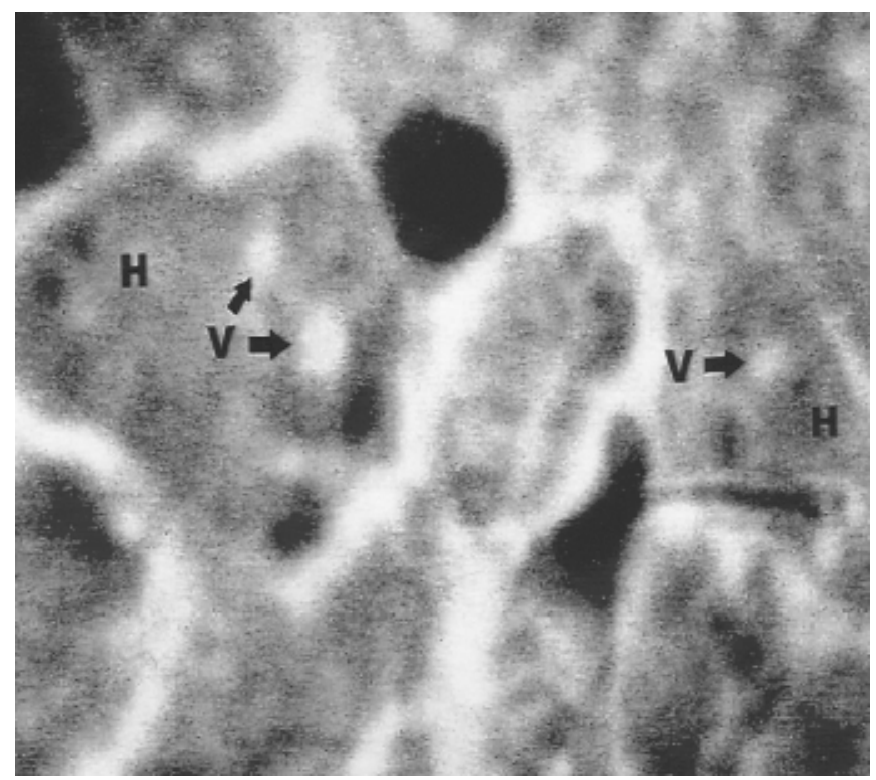

Figure 2: Liver of Gallus domesticus. Foci of altered hepatocytes (arrows) in the liver of $G$. domesticus. Foci are classified as vacuolated (V) and lymphocytes (L) according to their staining characteristics in chicks exposed to sublethal doses of phostoxin.

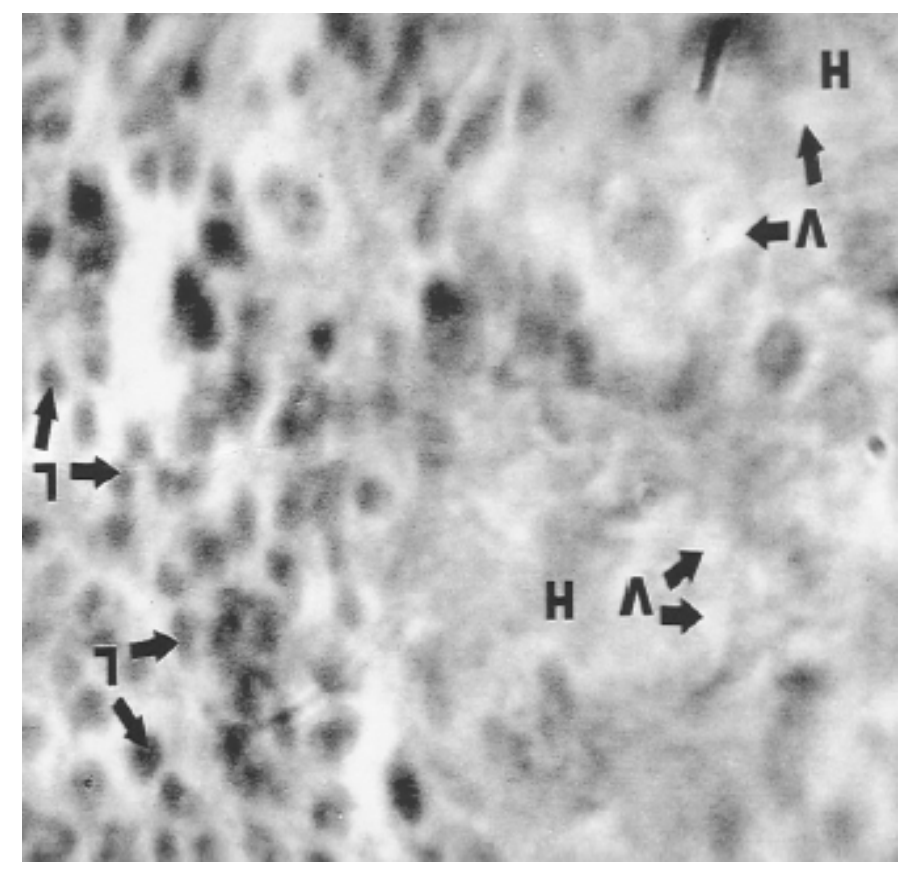

Figure 3: Liver of Gallus domesticus. Foci of altered hepatocytes (arrows) in the liver of $G$. domesticus. Foci are classified as vacuolated (V) and lymphocytes (L) according to their staining characteristics in chicks exposed to sublethal doses of actellic. 


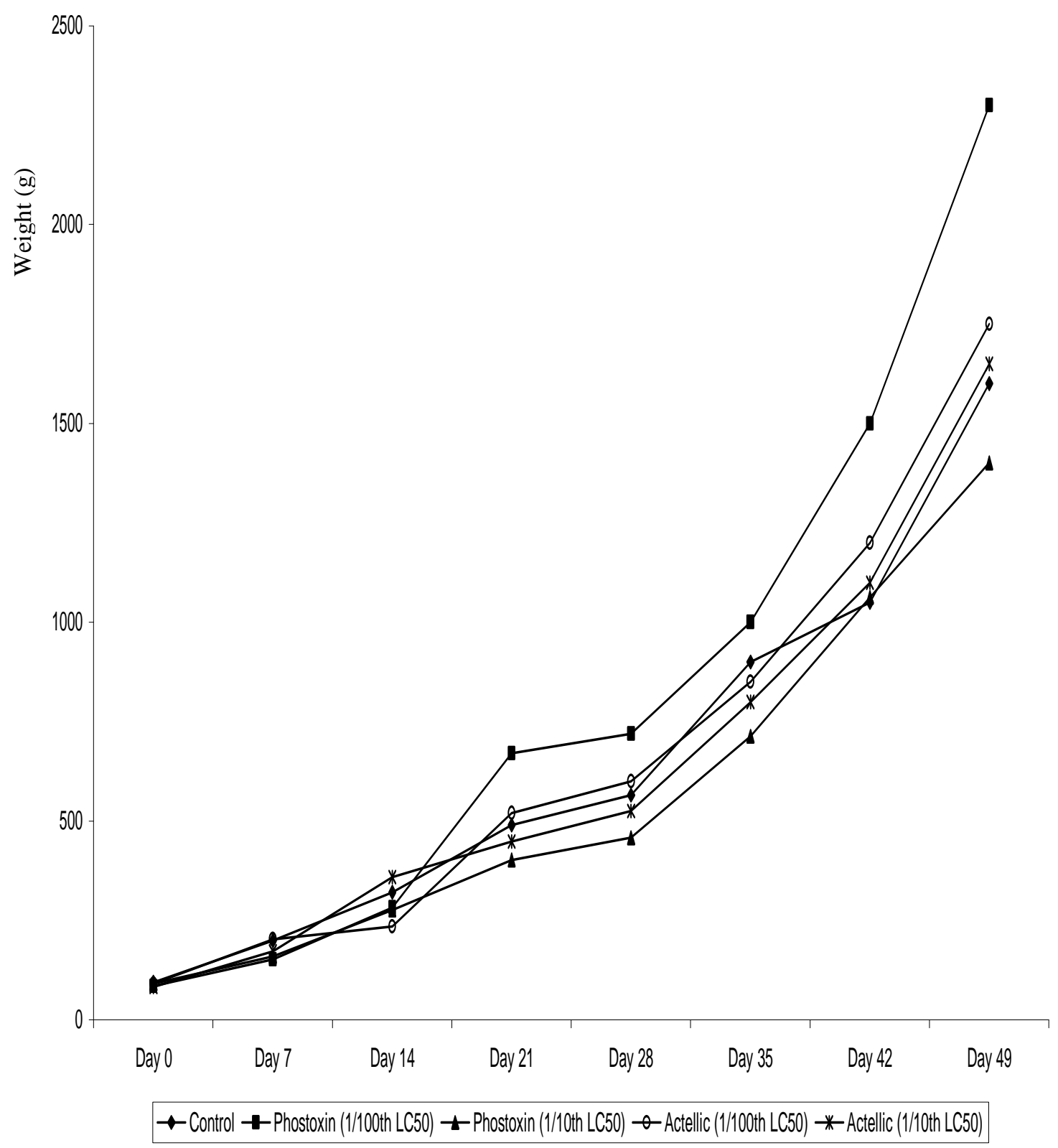

Figure 4: Weight changes in broiler chicks, Gallus domesticus exposed to sublethal concentrations of phostoxin and actellic over a 49-day period of observation. 
A. A. OTITOLOJU et al. / Int. J. Biol. Chem. Sci. 4(6): 2303-2313, 2010

Table 1: Relative acute toxicity of phostoxin and actellic against broiler chicks, Gallus domesticus.

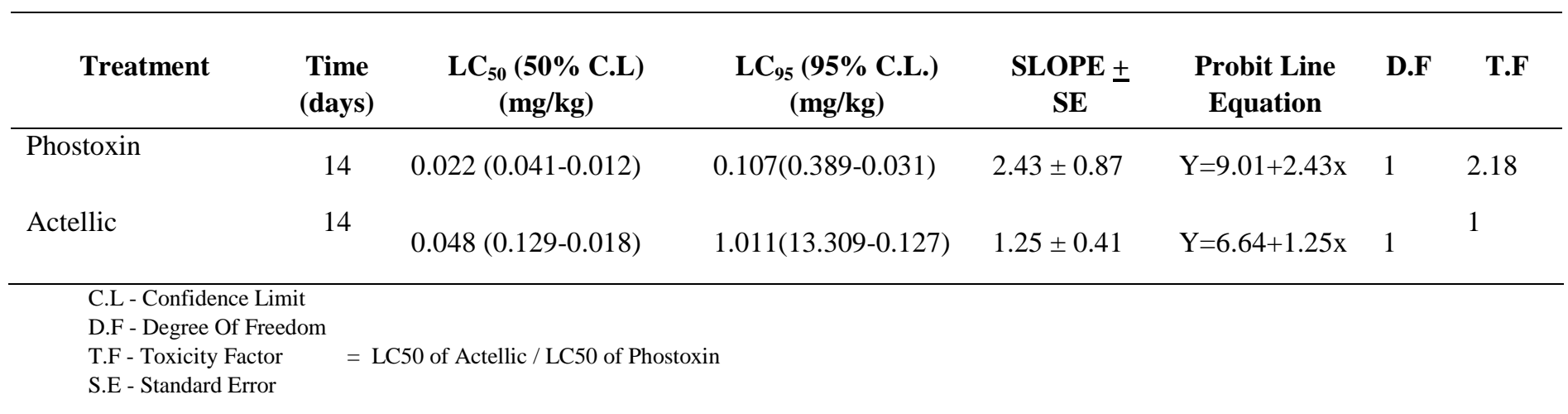

Table 2: Biochemical analysis of blood samples of broiler chicks (Gallus domesticus) exposed to sublethal doses of phostoxin over a 49-day period of observation.

\begin{tabular}{|c|c|c|c|}
\hline Parameters & Control & $\begin{array}{c}1 / 100^{\text {th }} \mathrm{LC50} \\
(0.002 \mathrm{mg} / \mathrm{kg})\end{array}$ & $\begin{array}{c}1 / 10^{\text {th }} \text { LC50 } \\
(0.02 \mathrm{mg} / \mathrm{kg})\end{array}$ \\
\hline Glucose $(\mathrm{mg} / \mathrm{dL}) *$ & $287.00 \pm 0.99$ & $332.90 \pm 5.37$ & $337.90 \pm 0.42$ \\
\hline Total protein $(\mathrm{mg} / \mathrm{dL})^{+}$ & $4.00 \pm 0.14$ & $3.00 \pm 0.14$ & $2.70 \pm 0.14$ \\
\hline $\mathrm{LDH}(\mathrm{IU} / \mathrm{L}) *$ & $879.00 \pm 4.24$ & $921.50 \pm 7.78$ & $932.50 \pm 4.95$ \\
\hline
\end{tabular}


Table 3: Mean level of blood biochemical parameters in broiler chicks, Gallus domesticus exposed to sublethal doses of actellic over a 49-day period of observation.

\begin{tabular}{|c|c|c|c|}
\hline Parameters & Control & $\begin{array}{l}1 / 100^{\text {th }} \text { LC50 } \\
(0.005 \mathrm{mg} / \mathrm{kg})\end{array}$ & $\begin{array}{l}1 / 10^{\text {th }} \text { LC50 } \\
(0.05 \mathrm{mg} / \mathrm{kg})\end{array}$ \\
\hline Glucose $(\mathrm{mg} / \mathrm{dL}) *$ & $284.45 \pm 3.32$ & $306.90 \pm 2.55$ & $313.50 \pm 0.99$ \\
\hline Total protein $(\mathrm{mg} / \mathrm{dL})^{+}$ & $7.07 \pm 3.75$ & $2.90 \pm 0.14$ & $2.75 \pm 0.21$ \\
\hline LDH (IU/L) * & $867.50 \pm 4.95$ & $881.00 \pm 2.83$ & $901.50 \pm 10.61$ \\
\hline
\end{tabular}

Values significantly higher $\left(^{*}\right)$ or lower $\left(^{+}\right)$than control $(\mathrm{P}<0.05)$

\section{DISCUSSION}

In this study, the use of phostoxin and actellic pesticides as livestock feed protectant was found to result in mortality of the chicks when the pesticide residue in their feed was high. Estimation of the potential risks associated with the use of both pesticides based on derived toxicity factor for the two pesticides showed that phostoxin has the potential to cause twice as much harm to the chicks than actellic. The differential toxicity between two organophosphate pesticides with similar chemical properties has been reported in literature. For instance, ATSDR (1993), Otitoloju and Don-Pedro (1998) and HSDB (2001) have reported differential toxicities between pesticides belonging to same chemical groupings. The differential toxicity of these pesticides is attributable to differences in the physical and chemical properties of the two chemicals which may determine the rate of penetration, mode of action and the rate of metabolism by organisms. The practical significance of the differences in toxicity for the two test pesticides is that if a choice of candidate pesticide is to be made between phostoxin and actellic for protection of livestock feeds in storage, actellic may be a better choice candidate since it is less toxic to the chicks and therefore offers a higher safety margin should a case of pesticide residue problem arise.

The biochemical analysis of blood samples of the chicks exposed to sublethal doses of both phostoxin and actellic in their food revealed that there was a consistent increase in the level of glucose and lactate dehydrogenase (LDH) enzyme in the blood of exposed chicks when compared to the control birds. This result is in agreement with the studies by Ceron et al. (1997) and Luskova et al. (2001) who reported an increase in glucose level in exposed organisms following exposure to diazinon, another organophosphate pesticide. Several other authors (Srivastava, 1981; Hill and Fleming, 1982; Singh \& Srivastava 1982; Natarajan 1989; Gill et. al., 1990 and Sancho et. al., 1992) have also reported increases in plasma lactate dehydrogenase (LDH) activity following exposure of test animals to another organophosphate pesticide, methylparathion.

The significant increase in glucose and LDH levels in blood of the exposed animals may be associated with damage to the liver, skeletal muscle or cardiac muscle which is due to the side effects of the organophosphate chemicals resulting in nutrient and energy in their food not to be properly digested and absorbed. This causes the stimulation of the gluconeogenic pathway whereby glycogen stores are being broken down and converted to glucose (Ceron et al., 1997). Also, non glucose precursors such as proteins are also broken down, in a bid to obtain glucose during the gluconeogenesis causing myoglobin (muscle protein) to also be broken down. The muscles are rich in LDH and its breakdown will result in the LDH spilling into the blood, hence the elevated levels for glucose and LDH in the blood of the exposed chicks. Elevated levels of glucose and LDH in the blood of avians either in the wild or poultry farms may therefore serve as good biomarkers of 
organophosphate related pesticide residue problem.

In this study, the level of total proteins in the blood of exposed chicks however reduced significantly compared to the control chicks. This is similar to the results of Sancho et al. (1992) and Khattak and Hafeez (1996) who reported a decrease in the total protein levels in eel Anguilla anguilla and carp, Cyprinion watsoni respectively, following exposure to an organophosphate pesticide, malathion. The reduction in total proteins in blood of exposed organisms may also be attributable to the side effect of organophosphate compounds whereby non glucose precursors such as proteins are also broken down, in a bid to obtain glucose. Therefore, the reduction in total proteins in blood of avians can also serve as a complementary biomarker to elevated levels of glucose and LDH for early detection of organophosphate pesticide stress in the environment.

The histopathological studies showed that there was a high prevalence of altered hepatocytes of the liver of chicks exposed to sublethal doses of the organophosphate pesticides. These alterations consist of hepatic vacuolation and lymphocytosis. According to Ansari et al. (1987), the liver is an organ that frequently undergoes changes when exposed to pesticides at sublethal doses. The study of the hepatic tissue of Brachydanio rerio showed hepatic vacuolations in organisms exposed to organophosphates, even when the level of exposure were those that were normally considered safe. Sakr and Gabr (1992) also observed that marked hepatic vacuolation was the major histopathological lesion seen in a study of fenvalerate (organophosphate) induced histopathological and histochemical changes in the catfish, Clarias gariepinus. Hepatic vacuolation in liver cells could therefore serve as a good biomarker of organophosphate pollution in the wild or farm.

The results of the weight change studies revealed that at the test sublethal doses of phostoxin and actellic, there was a gradual increase in the weight of the exposed and control chicks over the period of observation. There were also no significant differences in weight of birds exposed to the sublethal doses compared to the control birds. Weight measurements may therefore not serve any useful purpose of an early warning signal of organophosphate pesticide residue problem at related sublethal doses. The observation also indicate that the exposure of the birds to sublethal doses of $0.002-0.02 \mathrm{mg} / \mathrm{kg}$ of feed for phostoxin and $0.005-0.05 \mathrm{mg} / \mathrm{kg}$ of feed for actellic will not affect significantly the meat production of the farm. There is however the need for further investigation on the quality of meat produced especially its level of pesticides residue and egg production in exposed birds before such levels of the organophosphate pesticides can be acceptable in livestock feeds.

\section{Conclusion}

The elevation of glucose and $\mathrm{LDH}$ levels in blood of exposed birds combined with a reduction in total proteins and hepatic vacuolations in liver cells were observed in this study to be good biomarkers of organophosphate pesticide pollution in broiler chicks. These changes represent biological end-point of contaminants exposure and reinforce the application of biochemical and histopathological parameters as useful tools for early detection of impending pesticide residue related problems.

\section{REFERENCES}

Alimi T, Oluwasola SO, Adejobi AO. 2006. Optimal farm size for achieving enterprise objective and sustainability in poultry meat production in Osun State, Nigeria. World's Poult. Sci. J., 62: 525536.

Ansari BA, Aslam M, Kumar K. 1987. Diazinon toxicity, activities of acetylcholinesterase and phosphatases in the nervous tissue of Zebra Danio, Brachydanio rerio (Cyprinidae). Acta Hydrochim. Hydrobiol., 15: 301-306. 
Agency for Toxic Substances and Disease Registry (ATSDR). 1993. Toxicological profile for Aldrin/Dieldrin. TP-92/01. U.S. Department of Health and Human Services, Public Health Service.

Ceron JJ, Sancho E, Ferrando MD, Gutierrez C, Andreu E. 1997. Changes in carbohydrate metabolism in the eel. Anguilla anguilla during short-term exposure to diazinon. Toxicol. Environ. Chem., 60: 201-210.

Don-Pedro KN. 1980. A population explosion of Aphis crassivora (Koch), following DDT application in a cowpea plot (Vigna unguiculata) cultiva (prima). Nig. J. Nat. Hist., 14: 617-619.

Don-Pedro KN. 1989. Mode of action of fixed oils against eggs of Callosobruchus maculatus (F). Pestic. Sc., 26: 107-115.

Finney DY. 1971. Probit analysis ( $\left.{ }^{\text {rd }} \mathrm{edn}\right)$. Cambridge University Press: London.

Edsall CC. 1999. A blood chemistry profile for lake trout. J. Aq. Animal Health, 11: 81-86.

Gill TS, Pande J, Tewari H. 1990. Sublethal effects of an organophosphorus insecticide on certain metabolite levels in a freshwater fish, Puntius conchonius Hamilton. Pestic. Biochem. Physiol., 36: 290-299.

Hill EF, Fleming WJ. 1982. Anticholinesterase poisoning of birds: field monitoring and diagnosis of acute poisoning. Environ. Toxicol. Chem., 1: 27-38.

Hodge MCE, Morre S. 1972. Pirimiphosmethyl (PP 511): Teratological studies in the rat. Report from ICI Industrial Hygiene Research Laboratories.

Hazardous Substances Data Bank (HSDB). 2001. TOXNET (Toxicology Data
Network). Phosphorus. Retrieved from: http://toxnet.nlm.nih.gov/ICI Central Toxicology Laboratory.

Khattak IUD, Hafeez MA. 1996. Effect of malathion on blood parameters of the fish, Cyprinion watsoni. Pak. J. Zool., 28: 45-49.

Lusková V, Svoboda M, Koláfiová J. 2001. The effect of diazinon on blood plasma biochemistry in Carp (Cyprinus carpio L.). Acta Vet. Brno., 71: 117-123.

Natarajan GM. 1989. Changes in the carbohydrate metabolites during acute and chronic exposure of air breathing fish Channa striatus to oxydemeton methyl (metasystox). Comp. Physiol. Ecol., 14: 181-184.

Otitoloju AA, Don-Pedro KN. 1998. Laboratory evaluation of the toxicity of dieldrin and cypermethrin against three species of mosquito larvae and non-target tadpoles. J. Sci. Res. Dev., 3: 139 - 146.

Sakr SA, Gabr SA. 1992. Ultrastructural changes induced by diazinon and neopybuthrin in skeletal muscles of Tilapia nilotica. Bull. Environ. Contam. Toxicol., 48: 467-473.

Sancho E, Ferrando MD, Gamon M, Andreumoliner E. 1992. Organophosphorus diazinon induced toxicity in the fish Anguilla anguilla L. Comp. Biochem. Physiol., 103C: 351-356.

Singh HH, Srivastava AK. 1982. Effect of formothion on carbohydrate metabolism in Indian catfish (Heteropneustes fossilis). Environ. Res., 28: 335-339.

Srivastava AK. 1981. Effects of acute exposure of methyl parathion on carbohydrate metabolism of Indian catfish (Heteropneustes fossilis). Acta Pharmacol. Toxicol., 48: 26-34. 